\title{
Optimization and Prediction of Mechanical and Thermal Properties of Graphene/LLDPE Nanocomposites by Using Artificial Neural Networks
}

\author{
P. Noorunnisa Khanam, ${ }^{1}$ MA AlMaadeed, ${ }^{1,2}$ Sumaaya AlMaadeed, ${ }^{3}$ Suchithra Kunhoth, ${ }^{3}$ \\ M. Ouederni, ${ }^{4}$ D. Sun, ${ }^{5}$ A. Hamilton, ${ }^{5}$ Eileen Harkin Jones, ${ }^{6}$ and Beatriz Mayoral ${ }^{5}$ \\ ${ }^{1}$ Center for Advanced Materials, Qatar University, P.O. Box 2713, Doha, Qatar \\ ${ }^{2}$ Materials Science and Technology Program, Qatar University, P.O. Box 2713, Doha, Qatar \\ ${ }^{3}$ Department of Computer Science \& Engineering, Qatar University, P.O. Box 2713, Doha, Qatar \\ ${ }^{4}$ Qatar Petrochemical Company (QAPCO), Doha, Qatar \\ ${ }^{5}$ School of Mechanical \& Aerospace Engineering, Queen's University Belfast, Belfast BT9 5AH, UK \\ ${ }^{6}$ School of Engineering, University of Ulster, Newtownabbey BT37 0QB, UK \\ Correspondence should be addressed to MA AlMaadeed; m.alali@qu.edu.qa
}

Received 21 January 2016; Revised 19 April 2016; Accepted 21 April 2016

Academic Editor: De-Yi Wang

Copyright ( 2016 P. Noorunnisa Khanam et al. This is an open access article distributed under the Creative Commons Attribution License, which permits unrestricted use, distribution, and reproduction in any medium, provided the original work is properly cited.

The focus of this work is to develop the knowledge of prediction of the physical and chemical properties of processed linear low density polyethylene (LLDPE)/graphene nanoplatelets composites. Composites made from LLDPE reinforced with 1, 2, 4, 6, 8, and $10 \mathrm{wt} \%$ grade $\mathrm{C}$ graphene nanoplatelets (C-GNP) were processed in a twin screw extruder with three different screw speeds and feeder speeds $(50,100$, and $150 \mathrm{rpm})$. These applied conditions are used to optimize the following properties: thermal conductivity, crystallization temperature, degradation temperature, and tensile strength while prediction of these properties was done through artificial neural network (ANN). The three first properties increased with increase in both screw speed and C-GNP content. The tensile strength reached a maximum value at $4 \mathrm{wt} \% \mathrm{C}-\mathrm{GNP}$ and a speed of $150 \mathrm{rpm}$ as this represented the optimum condition for the stress transfer through the amorphous chains of the matrix to the C-GNP. ANN can be confidently used as a tool to predict the above material properties before investing in development programs and actual manufacturing, thus significantly saving money, time, and effort.

\section{Introduction}

The various forms and allotropes of carbon, such as carbon nanotubes [1], carbon fibre [2], graphite [3, 4], graphene [5], and graphene oxide, have attracted many researchers due to their exceptional physical and mechanical properties, such as high electrical conductivity and good thermal stability. This combination of superior properties with the simplicity of production of graphene-based materials is important in different applications such as electronic industry and sensors [6]. One of the most widely used applications of these graphene-based materials is in polymer composites with good mechanical, thermal, gas barrier, and electrical properties compared to the pure polymers [7].

Graphene-based composites can be processed into different shapes that serve the required applications with available processing methods. Graphene-based polymer composites have attracted many researchers in both academia and industry [8]. Several polymers, such as epoxy [9], PMMA [10], PVA [11], PS [12], and PP [13], were used as matrices to prepare graphene nanoplatelets composites [14].

Graphene nanoplatelets (GNPs) are novel nanofillers that consist of single or multiple graphitic planes and possess exceptional properties with high mechanical strength and 


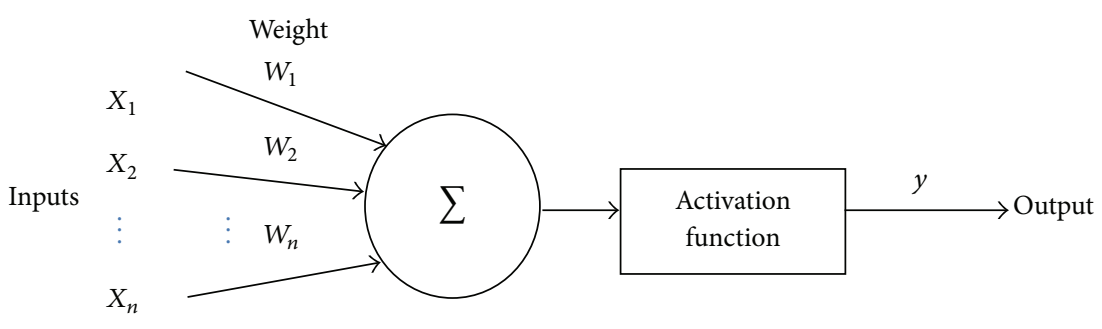

FIGURE 1: McCulloch and Pitts model of neuron.

chemical stability. GNPs have many advantages such as the cost effectiveness and the extremely high-specific surface area, which facilitates stress transfer at the composite interface and provides higher reinforcement compared to carbon nanotubes [6].

The performance and application of these polymer composites can be restricted due to the aggregation of graphene nanoplatelet sheets.

During the manufacturing of polymer composites, processing parameters such as temperature, screw speed, and $\mathrm{wt} \%$ of the filler can influence the final properties of the composites $[15,16]$. The study of these processing-property relationships is important to tailor the composites for specific applications. Generally, modeling these relationships includes mathematical understanding resulting from experimental data. This mathematical model can reduce the experimental work which is very cost effective in designing the composites. Artificial neural networks [17] are a class of mathematical modeling that can be used to efficiently explore and analyze the relationship between large sets of inputs and outputs and have been extensively applied to materials processing [18]. ANNs are well suited to approximate outputs even when they are nonlinear functions of the inputs, so that a generalized model can be built over the available data.

The basic and first model of ANN was proposed by McCulloch and Pitts, as shown in Figure 1. It consists of a neuron that computes the weighted sum of its input signals and produces an output of 1 if the sum is above a threshold; else it produces an output of 0 . The threshold function seen here is considered to be the activation function. Using positive weights indicates excitatory synapses, and using negative weights corresponds to inhibitory synapses. The threshold function can be replaced by many other activation functions such as piecewise linear, sigmoid, and Gaussian functions.

The mechanical, electrical, and thermal properties of graphene nanoplatelet composites can be strongly affected by several parameters during their manufacturing process. It would be a tedious task to experimentally determine the effect of all the possible combinations of these parameters.

The present study focuses on the GNPs/LLDPE nanocomposites which were prepared by melt processing with different extruder screw and feeder speeds. In this study we calculate and predict thermal, electrical, and tensile properties. Linear low density polyethylene (LLDPE) was used as the polymer matrix due to the good balance between

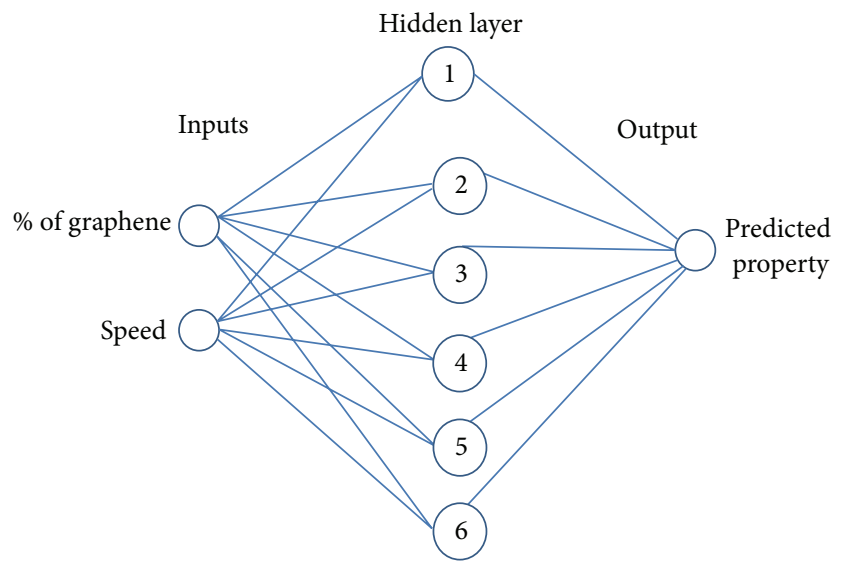

FIGURE 2: ANN architecture (prediction of required property).

rigidity and strength and relative ease of processing compared to other types of PE. By modifying the chain structure of the polymer by the reinforcement of nanoadditives (e.g., carbon additive), the mechanical properties of PE can be enhanced and new conductive paths are arranged in the material. Improvement in the electrical conductivity can also be achieved which can be applied in electronic industry such as static charge-dissipative materials.

An ideal solution is the implementation of a suitable prediction method based on the available experimental data points. To this end, we have developed an artificial neural network model to predict the thermal conductivity, crystallization temperature, degradation temperature, and tensile strength for graphene nanoplatelet/polymer composites. Figure 2 shows the ANN architecture of inputs (speed and composition of the additives) and outputs (predicted property).

\section{Experimental}

2.1. Materials. LLDPE with MFI of $1.0 \mathrm{~g} / 10 \mathrm{~min}$ and density of $0.918 \mathrm{~g} / \mathrm{cm}^{3}$ was kindly provided by QAPCO (Qatar), in powder form. LLDPE was mixed with a phenolic stabilizer to improve its thermal stability during extrusion.

Graphene nanoplatelets grade C (C-GNP) supplied by XG Sciences (USA) were used as a filler. C-GNP particles of submicron platelets have thickness of few nanometers and 
TABLE 1: List of extruded samples codes.

\begin{tabular}{|c|c|c|c|c|}
\hline Sample codes & Extruder speed (rpm) & Feeder speed $(\mathrm{kg} / \mathrm{h})$ & $\%$ of graphene nanoplatelets & $\%$ of LLDPE \\
\hline LLDGNPC 1 & 50 & 50 & 0 & 100 \\
\hline LLDGNPC 2 & 100 & 100 & 0 & 100 \\
\hline LLDGNPC 3 & 150 & 150 & 0 & 100 \\
\hline LLDGNPC 4 & 50 & 50 & 1 & 99 \\
\hline LLDGNPC 5 & 50 & 50 & 2 & 98 \\
\hline LLDGNPC 6 & 50 & 50 & 4 & 96 \\
\hline LLDGNPC 7 & 50 & 50 & 6 & 94 \\
\hline LLDGNPC 8 & 50 & 50 & 8 & 92 \\
\hline LLDGNPC 9 & 50 & 50 & 10 & 90 \\
\hline LLDGNPC 10 & 100 & 100 & 1 & 99 \\
\hline LLDGNPC 11 & 100 & 100 & 2 & 98 \\
\hline LLDGNPC 12 & 100 & 100 & 4 & 96 \\
\hline LLDGNPC 13 & 100 & 100 & 6 & 94 \\
\hline LLDGNPC 14 & 100 & 100 & 8 & 92 \\
\hline LLDGNPC 15 & 100 & 100 & 10 & 90 \\
\hline LLDGNPC 16 & 150 & 150 & 1 & 99 \\
\hline LLDGNPC 17 & 150 & 150 & 2 & 98 \\
\hline LLDGNPC 18 & 150 & 150 & 4 & 96 \\
\hline LLDGNPC 19 & 150 & 150 & 6 & 94 \\
\hline LLDGNPC 20 & 150 & 150 & 8 & 92 \\
\hline LLDGNPC 21 & 150 & 150 & 10 & 90 \\
\hline
\end{tabular}

the diameter is usually of about 2 micrometers. C-GNPs have an average surface area of about $500 \mathrm{~m}^{2} / \mathrm{g}$.

2.2. Preparation of LLDPE/Graphene Nanocomposites Pellets. $1,2,4,6,8$, and $10 \mathrm{wt} \%$ C-GNP reinforced LLDPE composites were processed in a twin screw extruder with three different screw speeds and feeder speeds (50, 100, and $150 \mathrm{rpm}$ ). The matrix material and graphene were mixed in a fivestage Brabender twin screw extruder. The temperature of the processing zones was in the range of $190-230^{\circ} \mathrm{C}$. Table 1 lists the sample codes and the various processing conditions employed. The mixtures were fed into the hopper of the extruder and then pushed through the various zones of the extruder before being cooled in water. Extruded samples were hot-pressed in a compression molding machine $\left(170^{\circ} \mathrm{C}\right)$ to produce sheet samples for mechanical testing.

\subsection{Characterization}

\subsubsection{Thermal Properties}

(1) Thermal Conductivity. The thermal conductivity of the C-GNPs/LLDPE composites was measured by a Hot Disk (Sweden) TPS 2500S instrument. The sample dimensions were $5 \mathrm{~cm} \times 2.5 \mathrm{~cm}$ with a thickness of $0.5 \mathrm{~cm}$.

(2) Thermal Degradation Temperature. Thermogravimetric analysis (TGA) of the C-GNPs/LLDPE composites was done using a Perkin Elmer 6 under a nitrogen atmosphere from ambient temperature to $700^{\circ} \mathrm{C}$ at a heating rate of $10^{\circ} \mathrm{C} /$ minute.

2.3.2. Crystallization Temperature $\left(T_{C}\right)$ and Crystallinity Percentage. The crystallization temperature was measured by using Perkin Elmer Pyris 7 differential scanning calorimetry (DSC) under nitrogen atmosphere, while maintaining a constant heating and cooling rate of $10^{\circ} \mathrm{C} /$ minute. The $\mathrm{C}$ GNPs/LLDPE composites were heated from room temperature to $220^{\circ} \mathrm{C}$ and held for 10 minutes at this temperature before being cooled to room temperature again. The crystallization temperature $\left(T_{\mathrm{C}}\right)$ was determined from the cooling cycle of the DSC curves.

The degree of crystallinity was calculated according to the following equation:

Degree of crystallinity

$$
=\left[\frac{(\text { Specific enthalpy of melting) }}{\text { (specific enthalpy for } 100 \% \text { crystalline PE } 288 \mathrm{~kJ} / \mathrm{kg})}\right]
$$

$$
\times 100 \text {. }
$$

2.3.3. Mechanical Testing. The tensile strength (fracture point) of the LLDPE/graphene composites was measured using a universal tensile testing machine at room temperature according to ASTM D638-10. Tensile strength of the five samples was tested for each composition, and the average value is reported. 


\subsection{Artificial Neural Network}

\subsubsection{Prediction Methodology}

Design and Training of Network. Our experimental platform consists of the "Neural Network Toolbox" available in MATLAB software package (version R2013a) [19]. The toolbox supports supervised learning with feedforward, radial basis, and dynamic networks as well as the unsupervised learning with self-organizing maps and competitive layers. It provides graphical tools for training neural networks to perform the tasks of data fitting, pattern recognition, clustering, and timeseries prediction.

2.4.2. Neural Network Architecture. Basically, a neural network consists of three types of neuron layers: input, hidden, and output layers. In the widely used "feedforward" networks, signal flows only from input to output in contrast to the "recurrent networks."

2.4.3. Learning. The networks learn/update their weights to achieve the desired outputs corresponding to the set of inputs by minimizing the error between the network's predicted outputs and actual measured outputs. These errors are used to update the weights starting from the output layer to the hidden layer and then to the input layer in the "backpropagation" mode of algorithms [20]. Backpropagation learning with sufficient number of hidden layers is successful in approximating any nonlinear functions and hence proves its suitability in signal prediction applications. But different initialization of weights yields different networks. Several optimization algorithms are used to optimize the weights, including gradient descent, conjugate gradients, quasi-Newton, and LevenbergMarquardt. The two parameters that are relevant to backpropagation learning are learning rate and momentum factor [21]. The learning rate determines the change of weights during the training. A larger learning rate causes a large change and thus it controls the learning speed. Momentum factor is used to speed up the network training. It determines the proportion of the previous weight changes that is to be added to the current weight changes. Both parameters are very important in determining learning speed and accuracy.

2.4.4. Activation Function. The activation functions are responsible for producing the outputs when supplied with weighted sum of input neurons [22]. Sigmoid activation functions with variants such as logistic, hyperbolic tangent, and arc tangent are the most commonly used. Feedforward networks usually comprise one or more hidden layers of sigmoid neurons followed by an output layer of linear neurons [19]. Multiple layers of neurons with nonlinear activation/transfer function help learning effectively the nonlinear relationships between input and output vectors. The linear output layer is most often used for function fitting problems.

2.4.5. Performance Evaluation. Efficiency of designed neural network in the prediction of the properties was evaluated in terms of the following parameters. (i) Mean Squared Error (MSE). It is calculated as the average squared difference between the predicted values and experimental data. Lower values indicate a better fit. Ideal value is zero which represents no error.

(ii) Regression $(R)$. It measures the correlation between the predicted and experimental values. The ideal value of 1 represents a close relationship whereas 0 represents a random relationship.

2.5. Experiments. For the simulation of neural network, we have used our data set of 21 samples. Input parameters used for the prediction are graphene content (wt\%) and speed. The predicted parameters are thermal conductivity, crystallization temperature, thermal degradation temperature, and tensile strength as described in Table 3. Separate neural network was built for each predicted parameter. The data set was split into three subsets as follows.

Training (50\%). 11 samples were randomly selected for network training.

Validation (25\%). Five samples were used to determine network generalization and stop training when generalization stops improving.

Testing (25\%). Five samples were used for the independent evaluation of prediction correctness after training.

Choosing the optimal number of hidden layers and their neurons is an important aspect of neural network based predictions. Most function approximation problems produce excellent results with single hidden layer [17]. The number of neurons in the hidden layer increases the power of the network but requires more computation and may cause overfitting. We used different number of hidden neurons to analyze their effects on the network's performance.

\section{Results and Discussion}

3.1. Thermal Conductivity. Thermal conductivity is related to the filler loading, its dispersion, and the interface between the filler and the matrix. GNPs have high aspect ratio and high surface area and are therefore expected to enhance heat transfer at the C-GNPs/polymer interface and thus improve the thermal conductivity of the composites. Thermal conductivity of GNPs/LLPDE composites was measured as a function of wt $\%$ of graphene and different speeds of extruder screw and feeder as shown in Figure 3. Thermal conductivity of GNPs/LLDPE composites increased with the increase of $\mathrm{wt} \%$ of graphene. The thermal conductivity of pure LLDPE was $0.37 \mathrm{w} / \mathrm{m} \cdot \mathrm{K}$ and that of the $10 \mathrm{wt} \%$ GNPs/LLDPE composites processed at $150 \mathrm{rpm}$ speed was $0.5 \mathrm{w} / \mathrm{m} \cdot \mathrm{K}$, which represents an enhancement by $42 \%$ compared with pure LLDPE. Thermal conductivity of $10 \mathrm{wt} \%$ GNPs/LLDPE composites processed at 100 and 50 speeds was increased by $27 \%$ and $23 \%$, respectively. These values are higher than the results reported by Zhu et al. [23] for $10 \%$ of the hybrid fillers of nitride particle and hollow glass microspheres even with the surface modifications of the fillers (less than $0.5 \mathrm{w} / \mathrm{m} \cdot \mathrm{K}$ ), but 


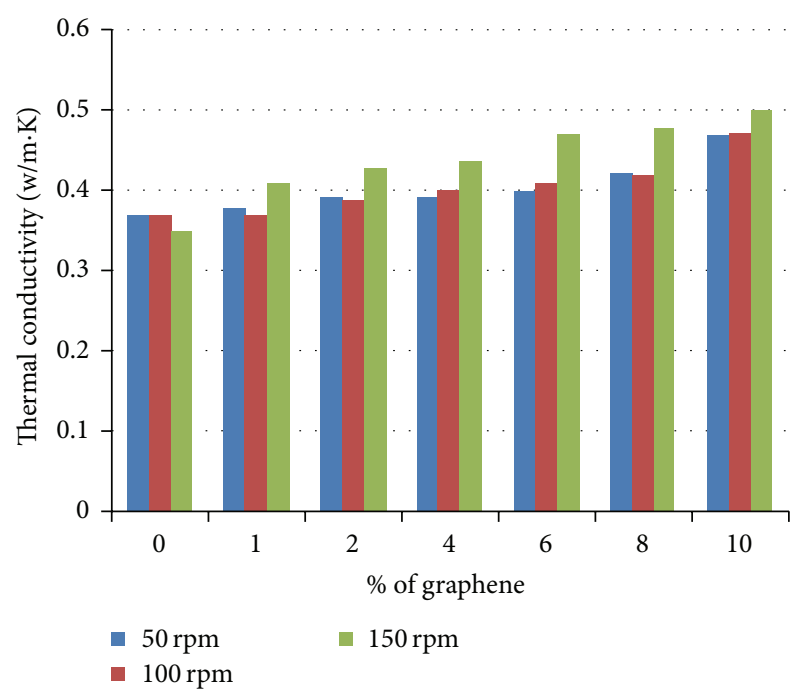

FIGURE 3: Effect of \% of graphene on thermal conductivity of LLDPE/C-GNPs composites at different screw/feeder speeds.

they are less than $0.6 \mathrm{w} / \mathrm{m} \cdot \mathrm{K}$ reported for the $10 \%$ of the high thermal conductive additive $\mathrm{Si}_{3} \mathrm{~N}_{4}$ [24].

The increase in thermal conductivity upon C-GNPs addition in the LLDPE matrix is due to the increase in the number of conductive channels and pathways inside the matrix. Other factors are the high aspect ratio and low interfacial thermal resistance between the platelets and the matrix [25].

Thermal conductivity of C-GNPs/LLDPE (Figure 3) was affected by the speed of extruder screw and feeder with higher speed giving increased thermal conductivity, which can be attributed to the better dispersion with the high speed. Lower speeds result in keeping the additives encapsulated in the matrix which means lower pathway networks.

This is similar to the results concluded by Zhang et al. [26] who explained that multistage stretching extrusion processing can improve the dispersion of the conductive additive (BN particles) in the PE matrix.

Network training was based on the Levenberg-Marquardt algorithm. The various parameter settings for the training are maximum number of epochs to train: 1000, minimum performance gradient: $1^{-15}$, and maximum validation failures: 6. Mean square error (MSE) and regression $(R)$ coefficients obtained for each setting of hidden neurons in the prediction of thermal conductivity are shown in Supplementary Table 1 in Supplementary Material available online at http://dx.doi.org/10.1155/2016/5340252. The selection of 11 hidden neurons gives the lowest MSE as well as high correlation coefficient.

The resulting performance curve for network training and the regression plot are shown in Figure 4. Figure 4(a) shows the performance plot with MSE as the goal for the training procedure. The best validation performance occurred at 2 epochs.

The training stopped when the validation error increased for 6 interactions which occurred at epoch 8. Test and validation set error follows the same trend which indicates the achievement of a good result. A linear regression between the network output and the corresponding target is shown in Figure 4(b) for training, validation, and testing and a correlation coefficient $R$-value of 0.9 was obtained for the full data set.

The experimental values are compared with the predicted values from ANN for thermal conductivity of CGNPs/LLDPE composites as shown in Table 4. From the table it is observed that predicted values and experimental values were very close to each other.

The mean relative error is very low, that is, $0.0258 \%$, between the experimental data and neural network prediction, which implies a good agreement between simulation and experimental results.

Figures 5(a) and 5(b) show experimental values and ANN outputs for thermal conductivity as a function of GNP wt $\%$ and screw and feeder speed, respectively. The columns show average measured values with $5 \%$ confidence interval, and the continuous line represents ANN output. These figures exhibit the good agreement between experimental data and ANN output.

3.2. Crystallization Temperature. DSC characterization was carried out to quantify any changes in crystallization temperature in the C-GNPs/LLDPE composites, and the results are presented in Figure 6. The crystallization temperatures of C-GNP/LLDPE composites were significantly higher than pure LLPDE polymer indicating the nucleation effect of CGNPs on the LLDPE matrix. The nucleating effect means that the onset of crystallization shifts to higher temperatures and crystallization starts earlier as the polymer is cooled down from the melt. This is also supported by the literature, which reports that graphene sheets can act as nucleating agents that increase the crystallinity of polymers [27]. Figure 6 also shows that the crystallization temperature increases with increasing C-GNPs wt\%. $10 \mathrm{wt} \%$ of C-GNPs has the highest crystallization temperature for all used speeds. The result is consistent with the literature [28] that the crystallinity of LLDPE increases with the graphene content.

The influence of the extruder speed on the crystallization temperature is not uniform, but generally a trend can be seen of higher crystallization temperatures with high screw and feeder speeds; this is likely due to the reduction in the number of agglomerates in the composite and the creation of more nucleation sites with the high shear rate.

Levenberg-Marquardt algorithm was used for training the network. The various parameter settings during the training were maximum number of epochs to train: 1000, minimum performance gradient: $1^{-15}$, and maximum validation failures: 4 . Supplementary Table 2 shows the MSE and the regression $(R)$ coefficients obtained for each setting of hidden neurons in the prediction of crystallization temperature. The sum of MSE for the training and test data indicates the accuracy of prediction [29]. Supplementary Table 2 shows that the selection of 4 hidden neurons gives the lowest MSE and a high correlation coefficient. The resulting performance curve for network training is shown in Figure 7(a) which is drawn by using MSE over the epochs and regression plots are shown in Figure 7(b). 


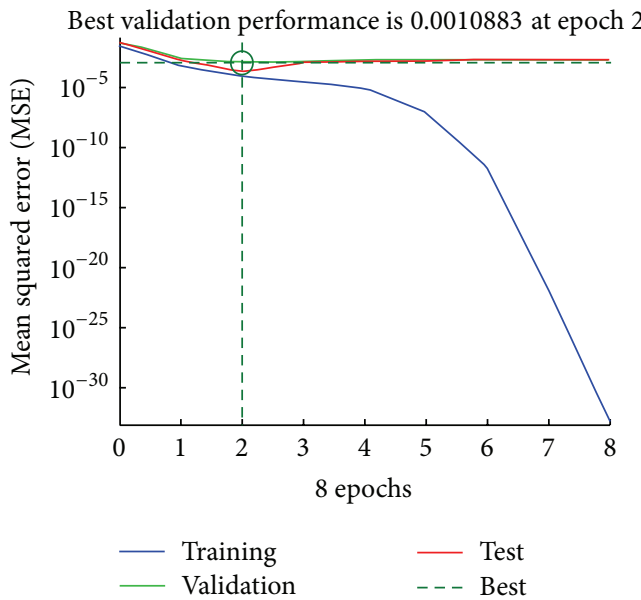

(a)
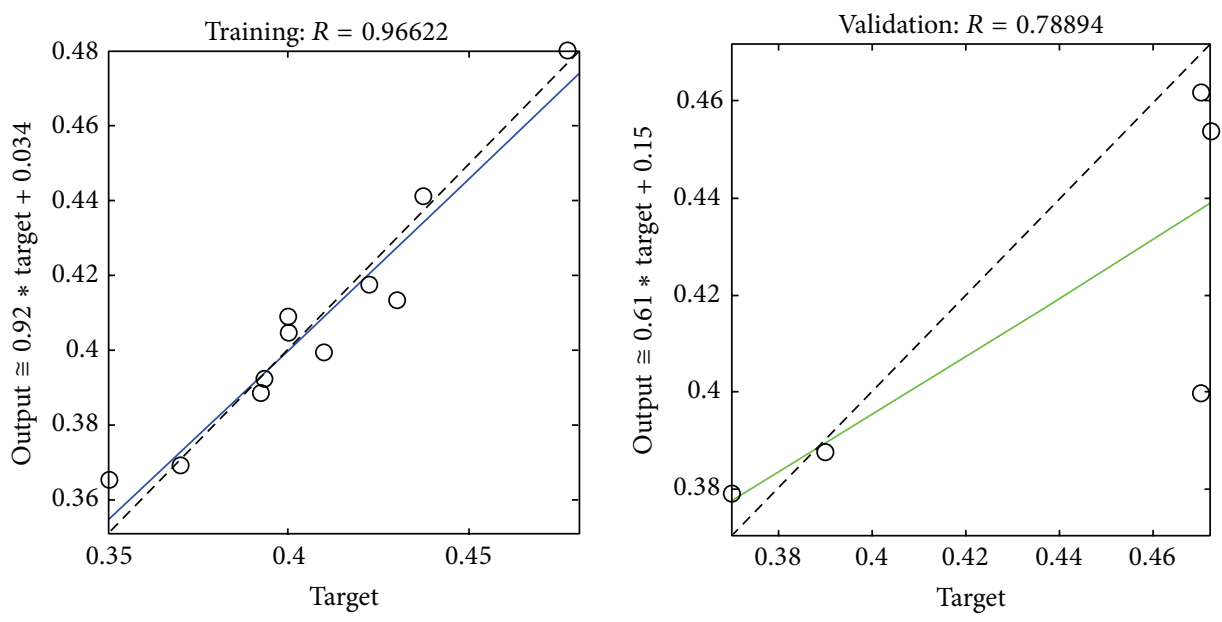

Data
Fit
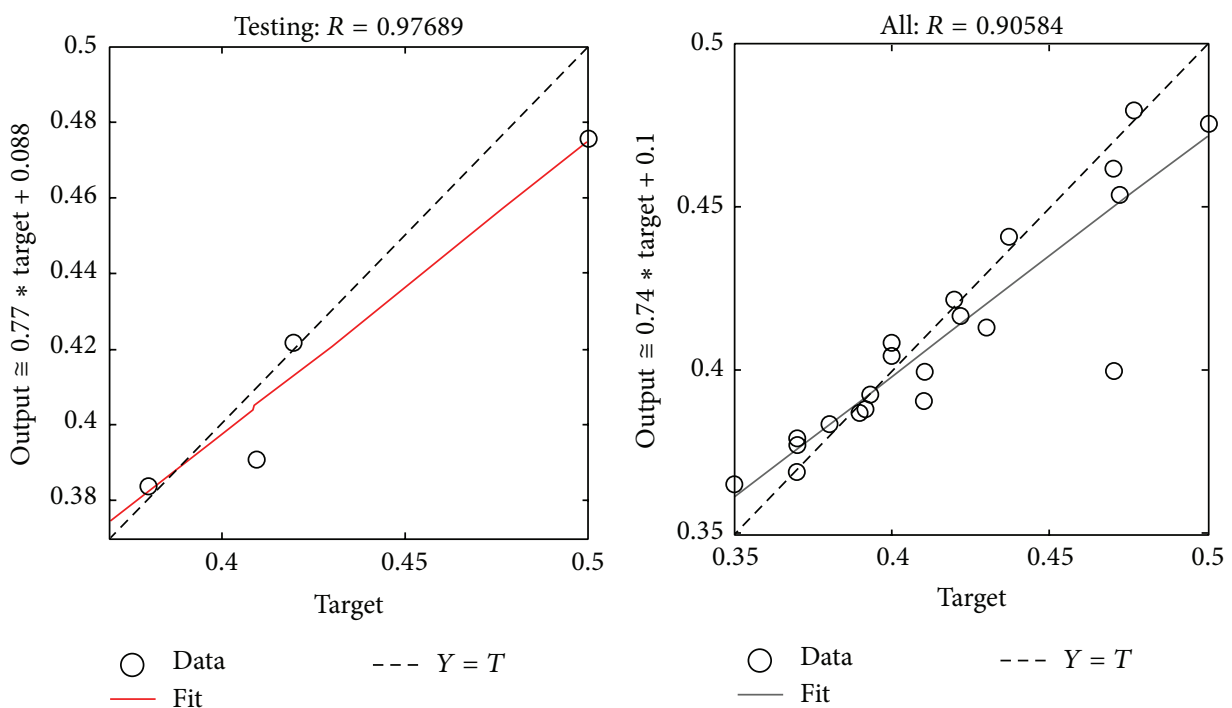

Data

-- $Y=T$

O Data

-- $Y=T$

- Fit

(b)

FIGURE 4: Neural network for the prediction of thermal conductivity: (a) performance plot and (b) regression plot. 


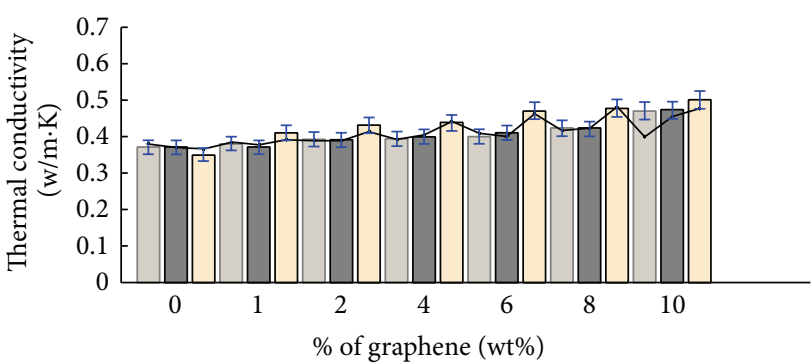

$\square$ Experimental values for $50 \mathrm{rpm}$

$\square$ Experimental values for $100 \mathrm{rpm}$

$\square$ Experimental values for $150 \mathrm{rpm}$

$\rightarrow$ Predicted values
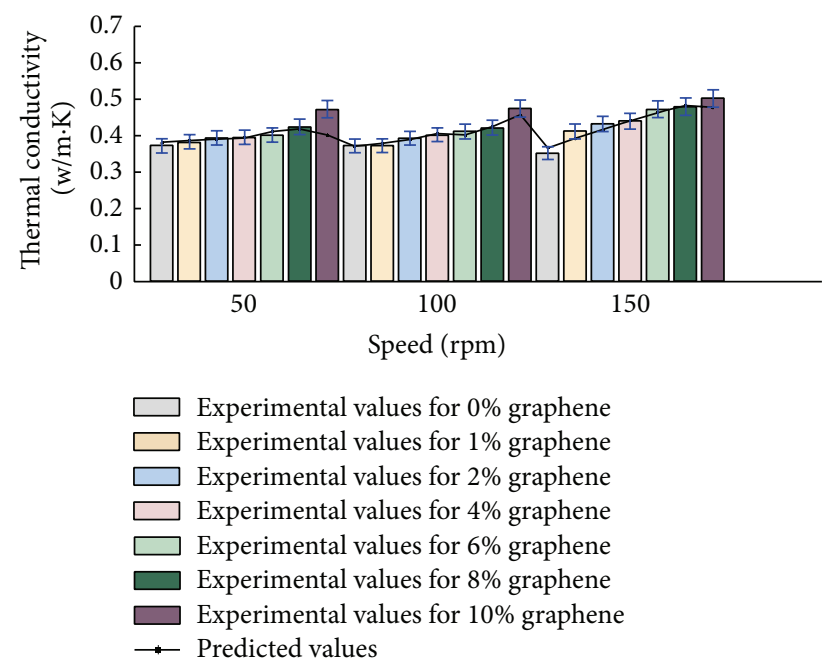

(b)

Figure 5: (a) Experimental versus predicted values of thermal conductivity of GNPs/LLDPE composites as a function of GNP wt\%. (b) Experimental versus predicted values of thermal conductivity of GNPs/LLDPE composites as a function of extruder screw and feeder speed.

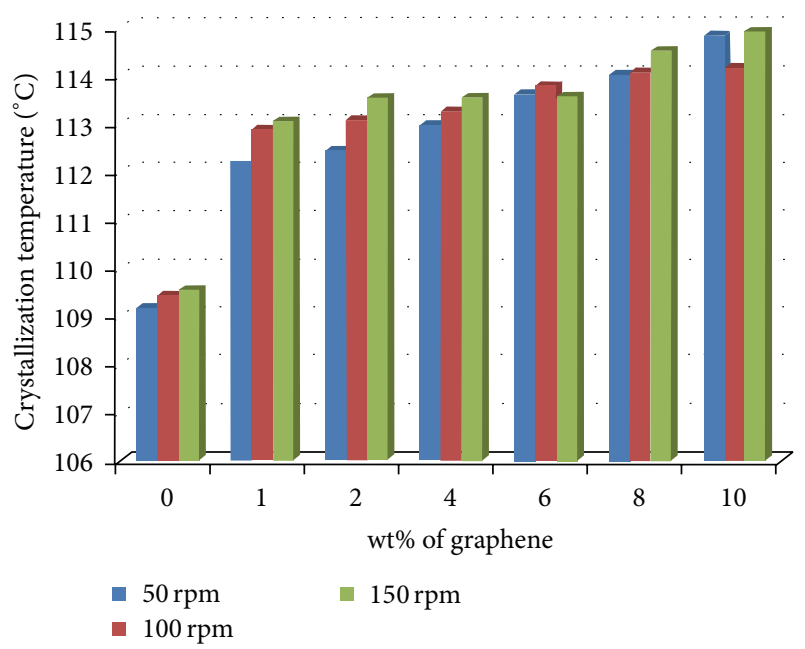

FIGURE 6: Effect of graphene addition on crystallization temperature of LLDPE/C-GNPs composites at different extruder speeds.

The performance plot shown in Figure $7(\mathrm{~b})$ indicates that the best validation performance occurred at epoch 10 . The training stopped when the validation error increased for 6 iterations which occurred at epoch 16 . Both the test and validation set errors followed similar trends which indicates a reasonable result. The regression plot (Figure 7(b)) shows the variation of predicted properties by ANN with corresponding experimental values, for each fraction of the data, namely, training, validation, testing, and whole data. A linear regression between the network output and the corresponding targets was shown in Figure 7(b). From this figure, correlation coefficient value ( $R$-value) for all responses is 0.989 , which indicates a good match between the experimental data and the ANN predictions. More detailed comparison between the experimental values and predicted values can be found in Table 5.

The average relative error in predicting the crystallization temperature of C-GNPs composites by the developed neural network model is low $(0.96 \%)$, which implies that predicted results were in good agreement with experimental results.

Figure 8 shows the crystallization temperature of CGNPs/LLDPE composites as a function of C-GNP wt $\%$ and of different extruder and feeder speeds. It can be seen from the figures that the predicted profile shows a good agreement with the experimental results. The figure shows that the well-trained neural networks can predict crystallization temperature as there is a functional relationship between the variables. The prediction of crystallization temperatures of polymer formulations is of great value in industrial development of polymer formulations and their behavior during melt processing.

3.3. Thermal Degradation Temperature. Figure 9 shows the thermal degradation temperature of the LLPDE and CGNPs/LLDPE composites with varying C-GNPs wt $\%$ and speed. LLDPE degrades at the lowest temperature, whereas the degradation temperature of graphene nanocomposites increases with increasing graphene content [28]. The results show that the addition of GNPs has a strong effect on the decomposition temperature of pure LLDPE and GNPs can act as an effective thermal barrier which prevents the thermal degradation of LLDPE. The LLDPE nanocomposite with $10 \mathrm{wt} \% \mathrm{C}$-GNPs has the highest thermal stability in the range of graphene composites tested. The enhancement in thermal stability of the C-GNPs/LLDPE composite can be attributed to the very high aspect ratio of GNPs which prevents the emission of small gaseous molecules during thermal degradation [30]. Addition of graphene nanoplatelets can form the charred layers on the surface of the composites which disturb 


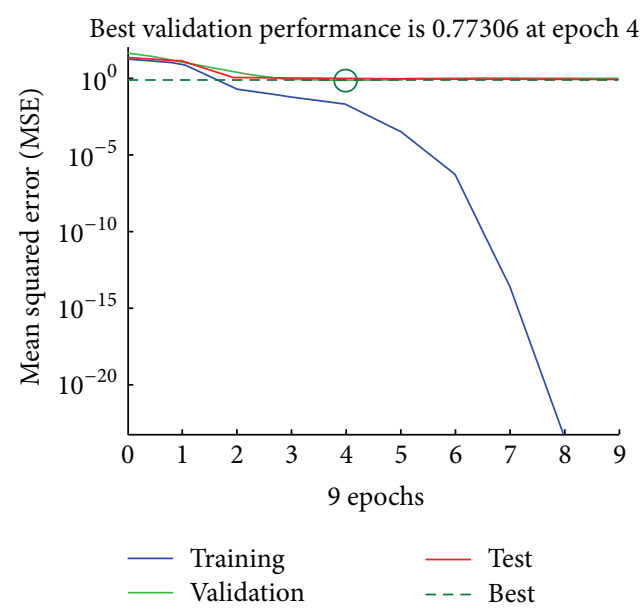

(a)
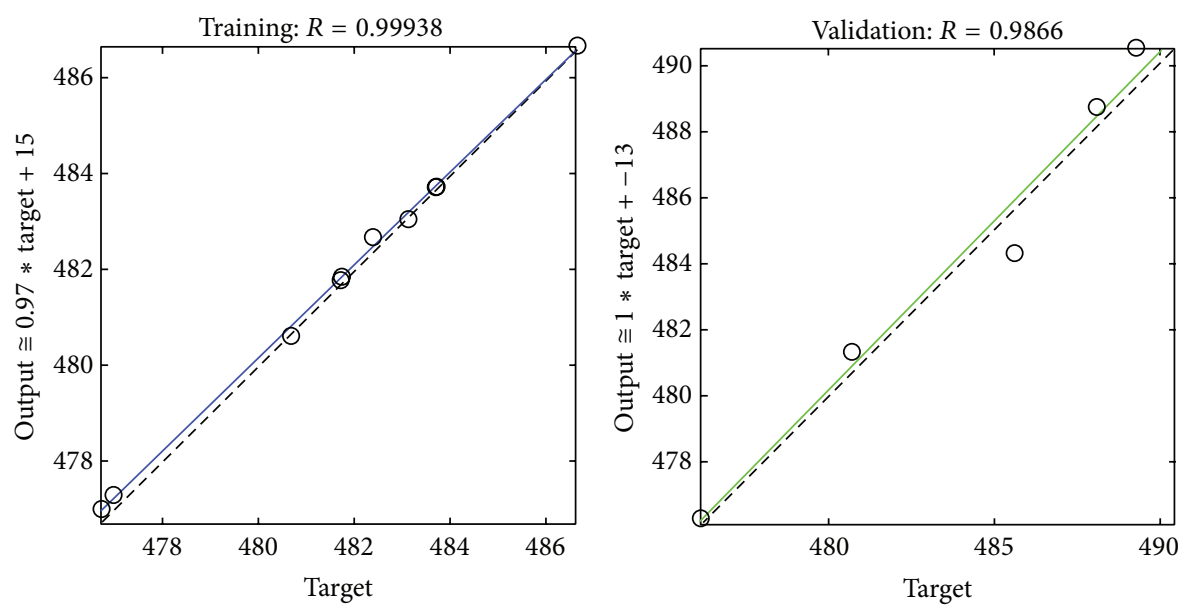

O Data

$---Y=T$

— Fit

Data $\quad--$
Fit
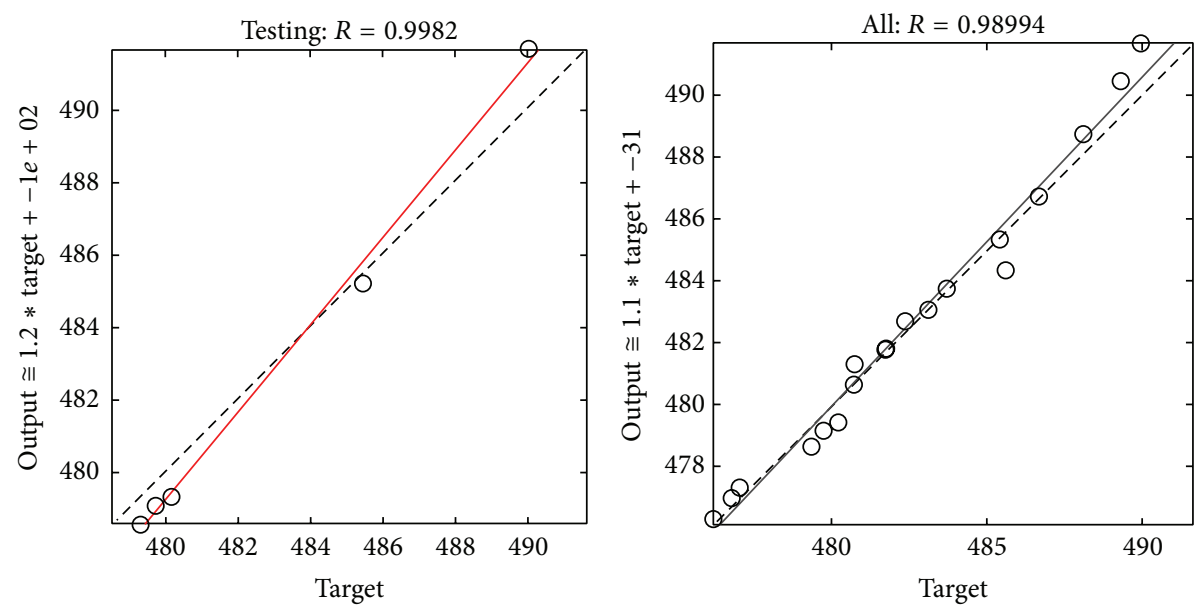

Data $\quad--Y=T$

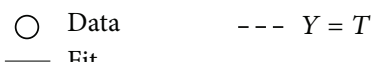

(b)

FIGURE 7: Neural network for the prediction of crystallization temperature: (a) performance plot and (b) regression plot. 


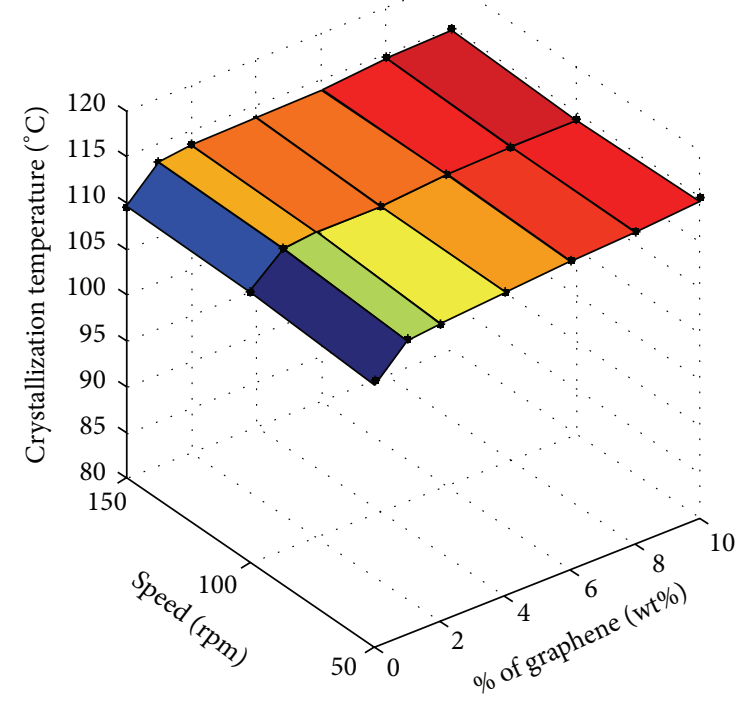

FIGURE 8: Predicted crystallization temperature of LLDPE/C-GNPs composites as a function of wt $\%$ and different speeds of LLDPE/CGNPs composites. The measured data are plotted as black points.

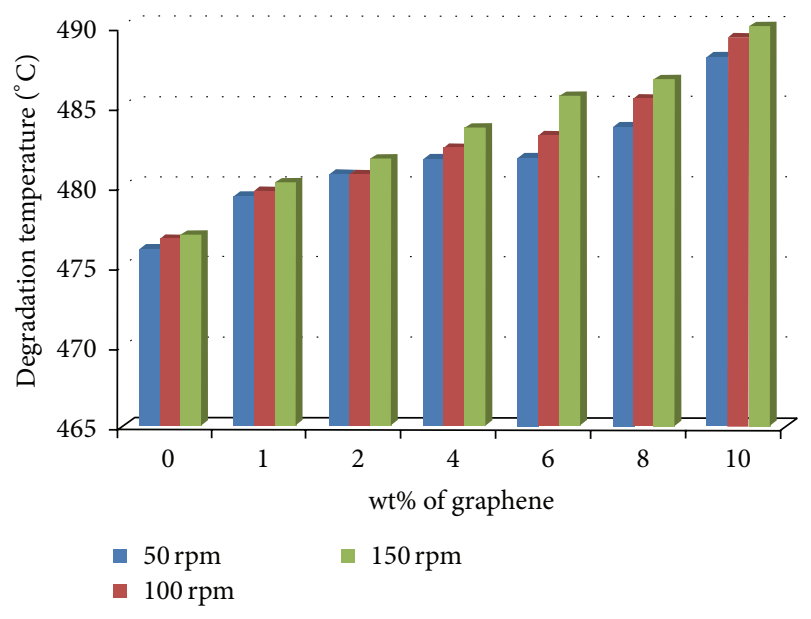

FigURE 9: Effect of \% of graphene on degradation temperatures of LLDPE/C-GNPs composites at different screw/feeder speeds.

the oxygen supply to the material underneath [31], leading to better thermal stability.

Similar results have been observed by other researchers, who reported that graphene increased the thermal stability of different kinds of polymers such as PP [32] and PS [33] and that the thermal stability increased with graphene content. Figure 9 also shows that increasing the extruder speed increases the degradation temperature. This could be due to better dispersion of the C-GNPs achieved at the higher screw and feeder speeds, leading to a better thermal barrier layer.

For training the network, Levenberg-Marquardt algorithm was used in this study. Various parameters settings were used during the training such as maximum number of epochs to train: 1000, minimum performance gradient: $1^{-15}$, and maximum validation failures: 5 . MSE and regression $(R)$ coefficients obtained for each setting of hidden neurons in the prediction of degradation temperature are shown in Supplementary Table 3.

The sum of MSE for the training and test data indicates the accuracy of the ANN predictions [29]. The selection of 5 hidden neurons achieved the lowest MSE and a high correlation coefficient; this is shown in Supplementary Table 3. The resulting performance curve for network training and regression plot are shown in Figure 10.

Figure 10(a) shows the performance plot including the training, validating, and test errors. The best validation performance occurred at epoch 10 , where the validation error is minimum. After epoch 10, both the test set error and validation set error display similar trends, until the validation was stopped at 16 epochs.

Figure 10(b) presents the result of regression plots for training, testing, validation, and the full data set. The regression value of $R=0.99$ indicates that the predicted values are very close to the ANN output and the model provides accurate predictions. Further comparison of experimental values and predicted values is provided in Table 6.

A low average relative error of $0.164 \%$ was obtained in the prediction of the thermal degradation temperature of the $\mathrm{C}$ GNPs/LLDPE composites by the developed neural network model. This very low error indicates that predicted results have good match with the experimental results.

Figure 11 shows the predicted degradation temperature of the LLDPE/C-GNPS composites with different C-GNPS wt $\%$ with different screw and feeder speeds. Neural network is accurate and the predicted profile shows a good agreement with the experimental results.

3.4. Tensile Properties. The relationships between tensile strength and C-GNPs wt $\%$ are shown in Figure 12. For the screw and feeder speed of $50 \mathrm{rpm}$, the tensile strength gradually increases with increasing C-GNP wt $\%$ and peaks at $4 \mathrm{wt} \%$ C-GNPs loading with an increase of $20.27 \%$. Further increasing of C-GNPs wt\% leads to a decrease in tensile strength, and the tensile strength measured for $10 \mathrm{wt} \% \mathrm{C}$ GNPs is lower than that of the virgin LLDPE. For the speed of $100 \mathrm{rpm}$, the variation of tensile strength of composites followed a similar trend, but the peak is at $2 \mathrm{wt} \% \mathrm{C}-\mathrm{GNPs}$ loading, corresponding to a total increase of $6.8 \%$ compared to virgin LLDPE. The tensile strength shows the most significant enhancement (47.5\% higher than virgin LLDPE) when the speed is $150 \mathrm{rpm}$ and C-GNP loading is $4 \mathrm{wt} \%$, indicating that there is a good efficient load transfer between graphene platelets and the LDPE matrix under such condition. This enhancement of the tensile properties was attributed to the fast flow and higher shear rate [34] obtained at $150 \mathrm{rpm}$, which corresponds to the highest interfacial interactions between the additives and the matrix. With further increase in C-GNP loading, the tensile strength for $150 \mathrm{rpm}$ speed drops dramatically to similar level as those for 50 and $100 \mathrm{rpm}$. 


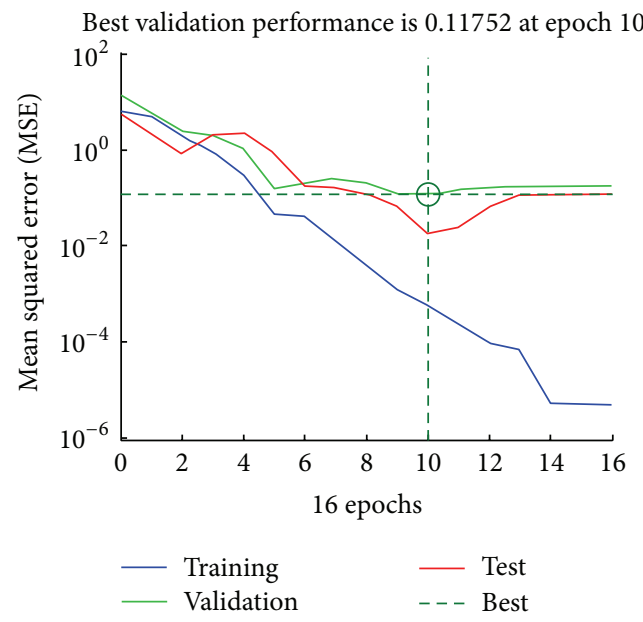

(a)
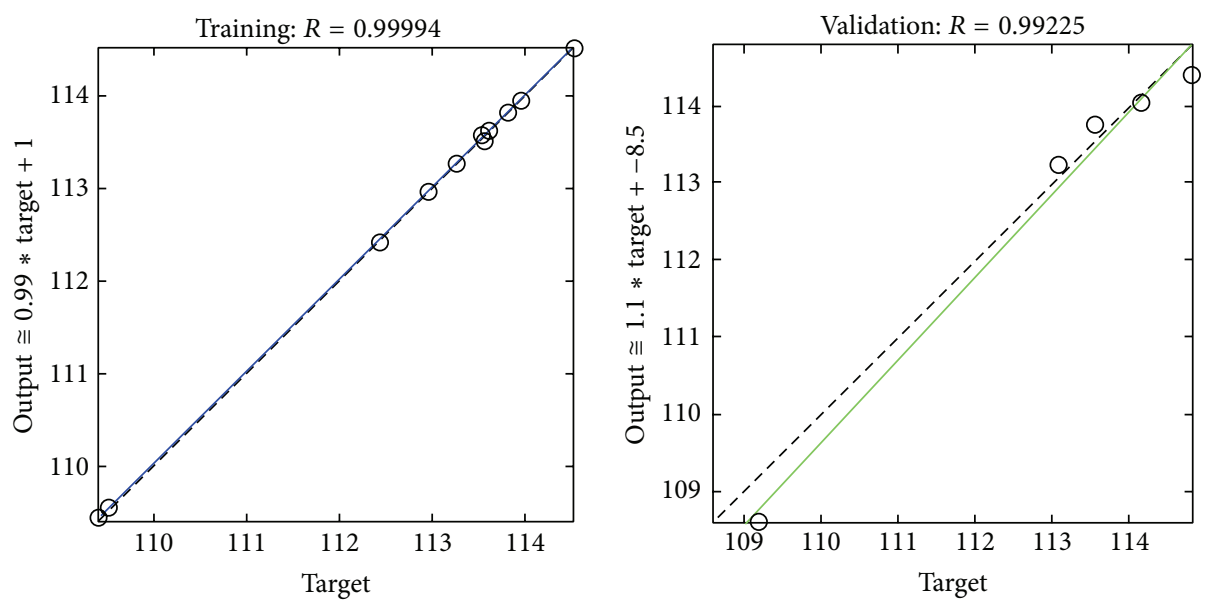

Data

Data

$---Y=T$
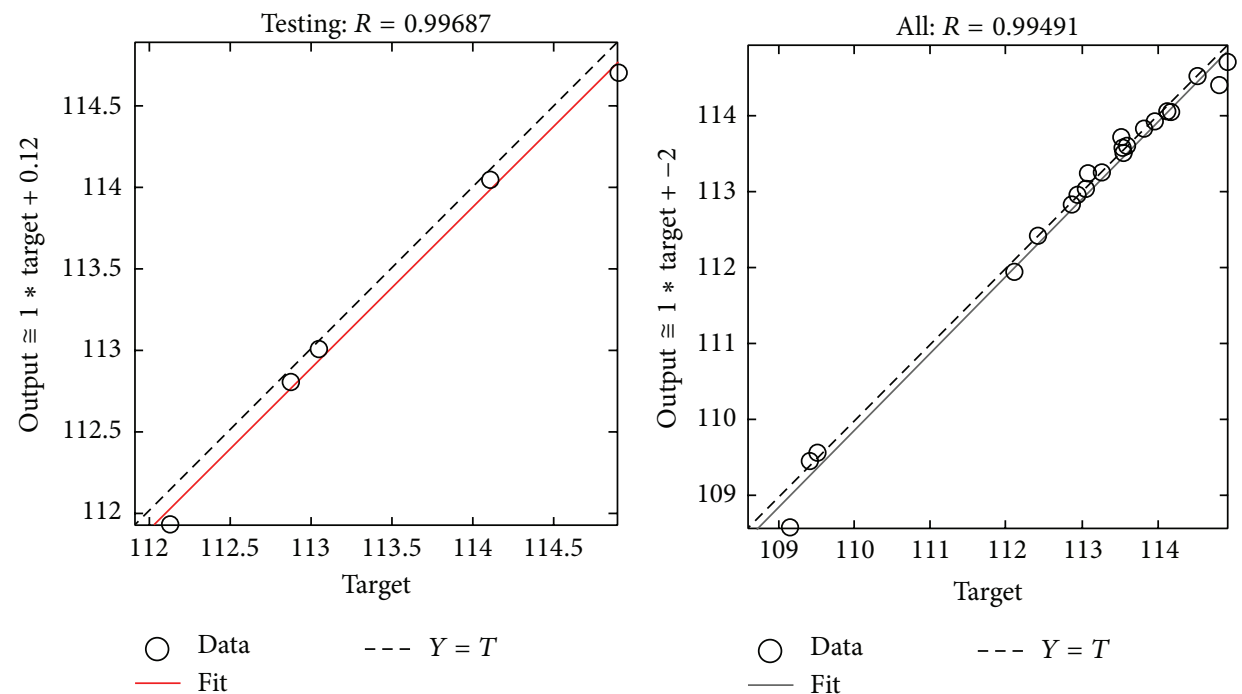

Data
Fit

$---Y=T$

- Fit

(b)

FIGURE 10: Neural network for the prediction of thermal degradation temperature: (a) performance plot and (b) regression plot. 


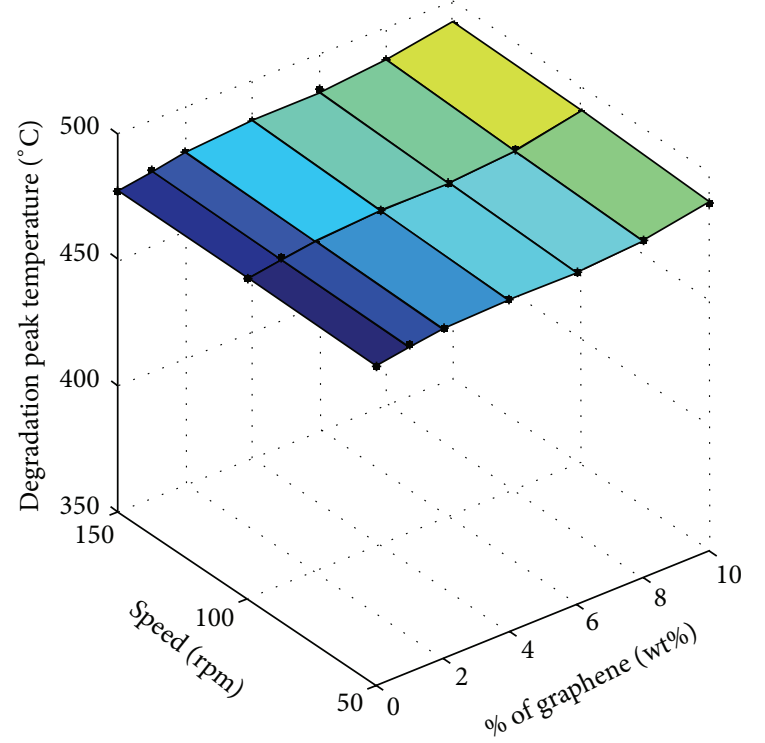

FIGURE 11: Predicted crystallization temperature of LLDPE/GNPs composites as a function of C-GNPs wt $\%$ and different speeds of LLDPE/GNPs composites. The measured data are plotted as black points.

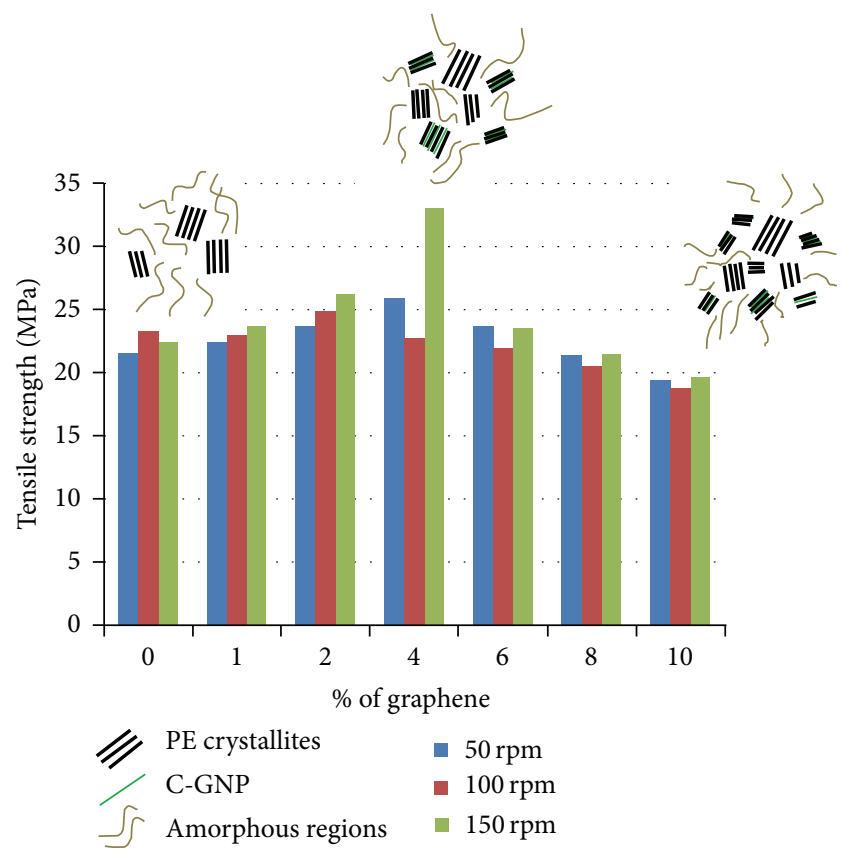

FIGURE 12: Effect of graphene filler content on tensile strength of LLDPE/C-GNPs composites at different screw/feeder speeds with the schematic diagram of morphology of the C-GNPs/LLDPE composites.

The crystallinity percentage was calculated from (1) as shown in Table 2 . The crystallinity percentage had the maximum value for the highest speed (150 rpm) at $4 \mathrm{wt} \%$ of GNPs. This table has a similar trend to the tensile strength which indicates that the increase in the crystalline regions limits the stretching of the chains in the amorphous regions and limits
TABLE 2: Crystallinity percentage of prepared composites at different speeds.

\begin{tabular}{lccc}
\hline C-GNPs wt $\%$ & $X_{c} \%$ at $50 \mathrm{rpm}$ & $X_{c} \%$ at $100 \mathrm{rpm}$ & $X_{c} \%$ at $150 \mathrm{rpm}$ \\
\hline 0 & 42.87 & 42.1 & 44 \\
1 & 46.8 & 46.7 & 46.8 \\
2 & 49.16 & 48.8 & 50.2 \\
4 & 53.8 & 52 & 62.22 \\
6 & 48.4 & 48.4 & 48.7 \\
8 & 48.5 & 48.2 & 48.8 \\
10 & 48.5 & 47.7 & 48.7 \\
\hline
\end{tabular}

the transfer of the load to the GNPs as shown in the diagram of the proposed morphology of the samples in Figure 12.

Levenberg-Marquardt algorithm was used for training the network. The various parameter settings during the training were maximum number of epochs to train: 1000, minimum performance gradient: $1^{-15}$, and maximum validation failures: 6 . The MSE and the regression $(R)$ coefficients obtained for each setting of hidden neurons in the prediction of tensile strength are shown in Supplementary Table 4.

The sum of MSE for the training and test data indicates the accuracy of prediction [29]. The selection of 6 hidden neurons gives the lowest MSE as well as a high correlation coefficient which is shown in Supplementary Table 4. The resulting performance curve for network training and regression plot are shown in Figure 13.

The performance plot in Figure 13(a) indicates that the best validation performance occurred at epoch 9 . The training stopped when the validation error increased for 6 iterations which occurred at epoch 15 . Both the test and validation set errors follow similar characteristics indicating achievement of a reasonable result. The regression plot (Figure 13(b)) shows the variation of predicted properties by ANN with corresponding experimental values, for each fraction of the data, namely, training, validation,testing, and whole data. A linear regression between the network output and the corresponding targets is shown in Figure 13(b). From this figure, correlation coefficient value ( $R$-value) for all responses is 0.933 which indicates a good matching between the experimental data and prediction of the neural network model. A detailed comparison between the experimental and predicted values is given in Table 7 .

The average relative error in predicting the tensile strength of nanocomposites by the developed neural network model is found to be very low (0.0396), indicating that predicted results matched the experimental results.

Figure 14(a) shows the comparison between experimental and predicted values from ANN for the LLDPE/GNPs composites with different wt $\%$ of graphene. The figure clearly shows that predicted values are in good agreement with the experimental data.

Comparison of experimental and predicted values of LLDPE/GNPs composites with different speeds was observed in Figure 14(b). A good agreement between the predicted and experimental values is seen according to the figure. 


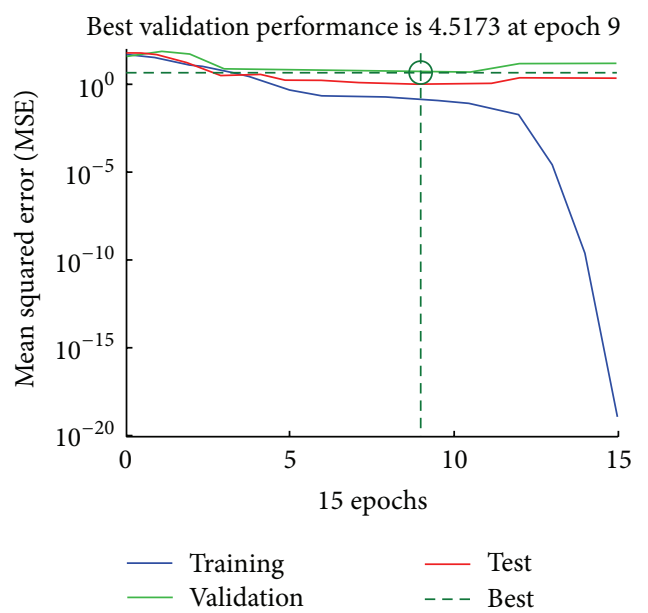

(a)
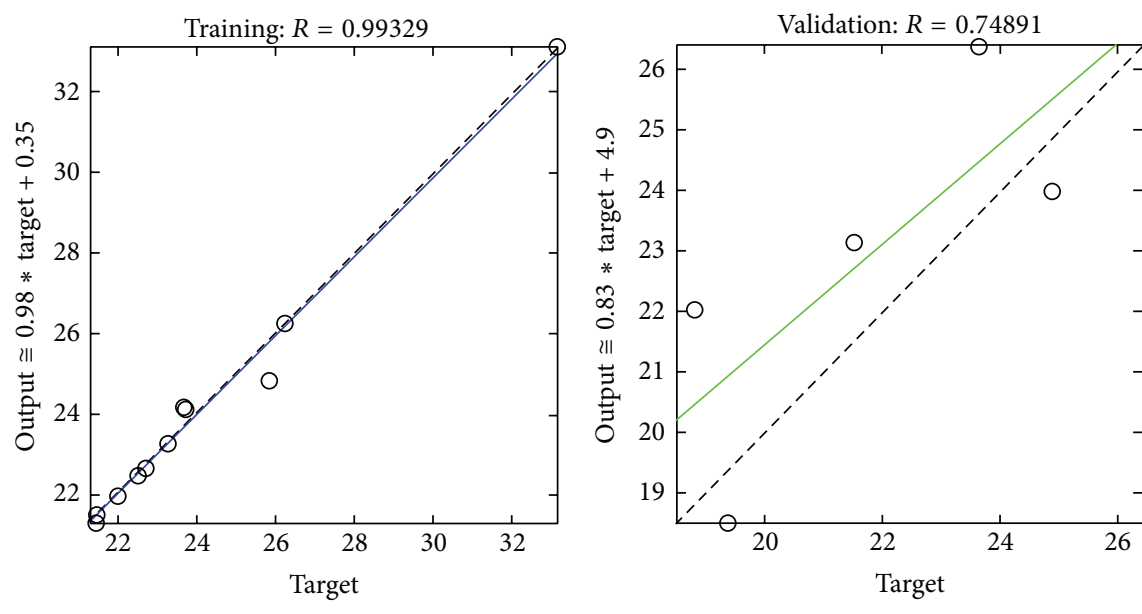

Data

$---Y=T$

Data

$---Y=T$

Fit
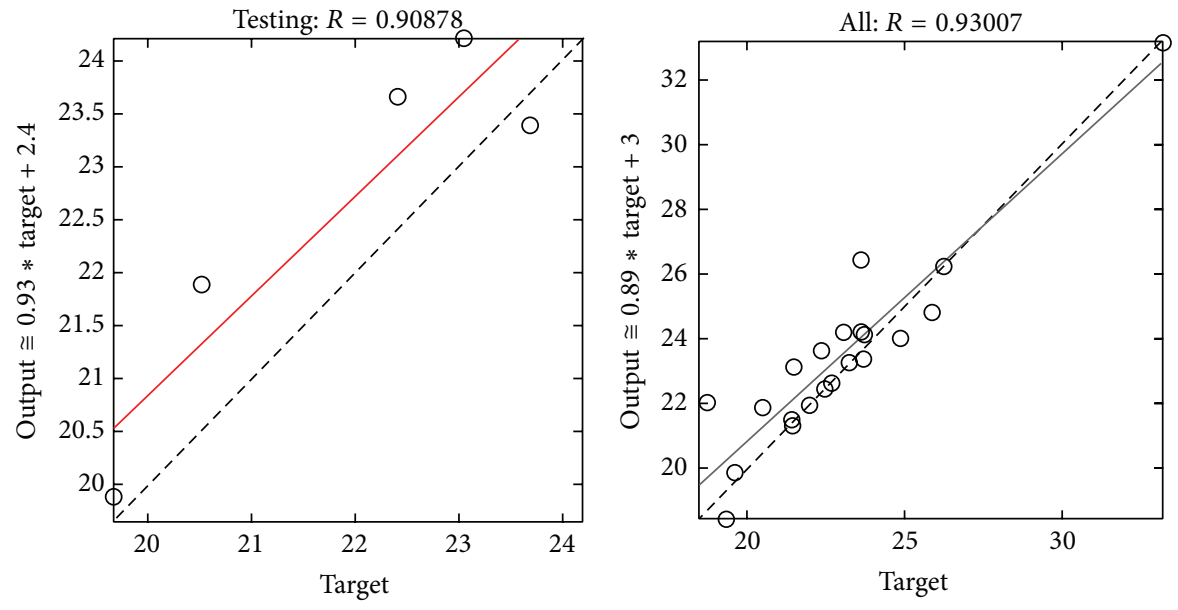

Data
-

Data

$---Y=T$

(b)

FIgURE 13: Neural network for the prediction of tensile strength: (a) performance plot and (b) regression plot. 
TABLE 3: Experimental data set.

\begin{tabular}{|c|c|c|c|c|c|c|c|}
\hline $\begin{array}{l}\text { Sample } \\
\text { number }\end{array}$ & $\begin{array}{c}\% \text { of } \\
\text { graphene }\end{array}$ & Speed & $\begin{array}{c}\text { Tensile strength } \\
(\mathrm{MPa})\end{array}$ & $\begin{array}{c}\text { Thermal } \\
\text { conductivity } \\
(\mathrm{w} / \mathrm{m} \cdot \mathrm{K})\end{array}$ & $\begin{array}{c}\text { Degradation } \\
\text { temperature }\left({ }^{\circ} \mathrm{C}\right)\end{array}$ & $\begin{array}{l}\text { Crystallization } \\
\text { temperature }\left({ }^{\circ} \mathrm{C}\right)\end{array}$ & Data partition \\
\hline 1 & 0 & 50 & 21.5 & 0.37 & 476.12 & 109.18 & Validation \\
\hline 2 & 0 & 100 & 23.27 & 0.37 & 476.72 & 109.43 & Training \\
\hline 3 & 0 & 150 & 22.49 & 0.35 & 477 & 109.53 & Training \\
\hline 4 & 1 & 50 & 22.4 & 0.38 & 479.36 & 112.13 & Testing \\
\hline 5 & 1 & 100 & 23.05 & 0.37 & 479.73 & 112.88 & Testing \\
\hline 6 & 1 & 150 & 23.7 & 0.41 & 480.2 & 113.05 & Testing \\
\hline 7 & 2 & 50 & 23.7 & 0.39 & 480.7 & 112.43 & Training \\
\hline 8 & 2 & 100 & 24.87 & 0.39 & 480.7 & 113.1 & Validation \\
\hline 9 & 2 & 150 & 26.26 & 0.43 & 481.7 & 113.55 & Training \\
\hline 10 & 4 & 50 & 25.86 & 0.39 & 481.73 & 112.95 & Training \\
\hline 11 & 4 & 100 & 22.7 & 0.4 & 482.4 & 113.26 & Training \\
\hline 12 & 4 & 150 & 33.13 & 0.437 & 483.7 & 113.54 & Training \\
\hline 13 & 6 & 50 & 23.66 & 0.4 & 481.76 & 113.6 & Training \\
\hline 14 & 6 & 100 & 22 & 0.41 & 483.11 & 113.8 & Training \\
\hline 15 & 6 & 150 & 23.63 & 0.47 & 485.62 & 113.55 & Validation \\
\hline 16 & 8 & 50 & 21.44 & 0.42 & 483.66 & 113.95 & Training \\
\hline 17 & 8 & 100 & 20.52 & 0.42 & 485.42 & 114.1 & Testing \\
\hline 18 & 8 & 150 & 21.47 & 0.477 & 486.64 & 114.5 & Training \\
\hline 19 & 10 & 50 & 19.38 & 0.47 & 488.09 & 114.81 & Validation \\
\hline 20 & 10 & 100 & 18.8 & 0.472 & 489.28 & 114.17 & Validation \\
\hline 21 & 10 & 150 & 19.65 & 0.5 & 490 & 115 & Testing \\
\hline
\end{tabular}

TABLE 4: Prediction results of thermal conductivity for test samples.

\begin{tabular}{|c|c|c|c|c|c|}
\hline Sample number & 4 & 5 & 6 & 17 & 21 \\
\hline $\begin{array}{l}\text { Measured value } \\
\text { (thermal conductivity } \\
(\mathrm{w} / \mathrm{m} \cdot \mathrm{K}))\end{array}$ & 0.38 & 0.37 & 0.41 & 0.42 & 0.50 \\
\hline $\begin{array}{l}\text { Predicted value (thermal } \\
\text { conductivity }(\mathrm{w} / \mathrm{m} \cdot \mathrm{K}))\end{array}$ & 0.38 & 0.38 & 0.39 & 0.42 & 0.48 \\
\hline
\end{tabular}

TABLE 5: Prediction results of crystallization temperature for test samples.

\begin{tabular}{lccccc}
\hline Sample number & 4 & 5 & 6 & 17 & 21 \\
\hline $\begin{array}{l}\text { Measured value } \\
\text { (crystallization }\end{array}$ & 112.13 & 112.88 & 113.05 & 114.10 & 114.90 \\
$\begin{array}{l}\text { temperature }{ }^{\circ} \mathrm{C} \text { ) } \\
\begin{array}{l}\text { Predicted value } \\
\text { (crystallization }\end{array}\end{array}$ & 111.92 & 112.81 & 113.02 & 114.05 & 114.70 \\
$\begin{array}{l}\text { temperature } \\
{ }^{\circ} \mathrm{C} \text { ) }\end{array}$ & & & & & \\
\hline
\end{tabular}

\section{Conclusions}

Development of nanocomposite formulations and actual manufacturing of these materials on melt processing equipment can be costly and time consuming. Variables such as additives $w t \%$ and speed of the extruder are two major parameters that can affect the optimization of required properties. The results in this study proved the ability of
TABLE 6: Experimental and predicted degradation temperature for test samples.

\begin{tabular}{|c|c|c|c|c|c|}
\hline Sample number & 4 & 5 & 6 & 17 & 21 \\
\hline $\begin{array}{l}\text { Measured value } \\
\text { (degradation } \\
\text { temperature }{ }^{\circ} \mathrm{C} \text { ) }\end{array}$ & 479.36 & 479.73 & 480.20 & 485.42 & 490 \\
\hline $\begin{array}{l}\text { Predicted value } \\
\text { (degradation } \\
\left.\text { temperature }{ }^{\circ} \mathrm{C}\right)\end{array}$ & 478.60 & 479.12 & 479.40 & 485.26 & 491.66 \\
\hline
\end{tabular}

artificial neural network to predict the complex relationship between screw (and feeder) speed and wt\% of GNPs filler and the resulting thermal conductivity, crystallization temperature, degradation temperature, and tensile strength of the composite materials. The first three parameters have a trend of increasing values with the increase of GNPs wt\% and the speed and reached $0.5(\mathrm{w} / \mathrm{m} \cdot \mathrm{K}), 115^{\circ} \mathrm{C}$, and $490^{\circ} \mathrm{C}$, respectively, for the $10 \mathrm{wt} \%$ of GNPs at speed of $150 \mathrm{rpm}$ due to the uniform distribution and increase in crystallinity inside the composite. The tensile strength reached a maximum value of $33.13 \mathrm{MPa}$ at $4 \mathrm{wt} \%$ of GNPs and speed of $150 \mathrm{rpm}$; this can be due to the existence of a sufficient amount of amorphous chains that are stretched during the tensile tests and acted to transfer the load to the GNPs.

The high correlation coefficients and small errors obtained ensure the accuracy of the training process. 

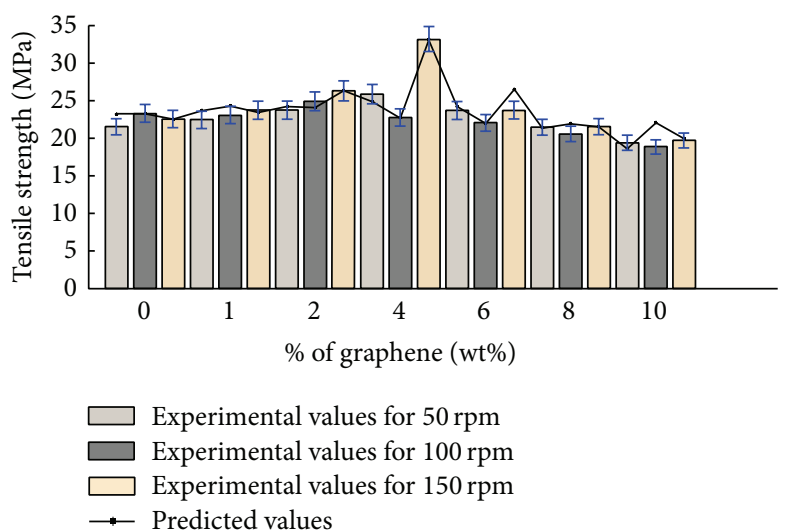

(a)
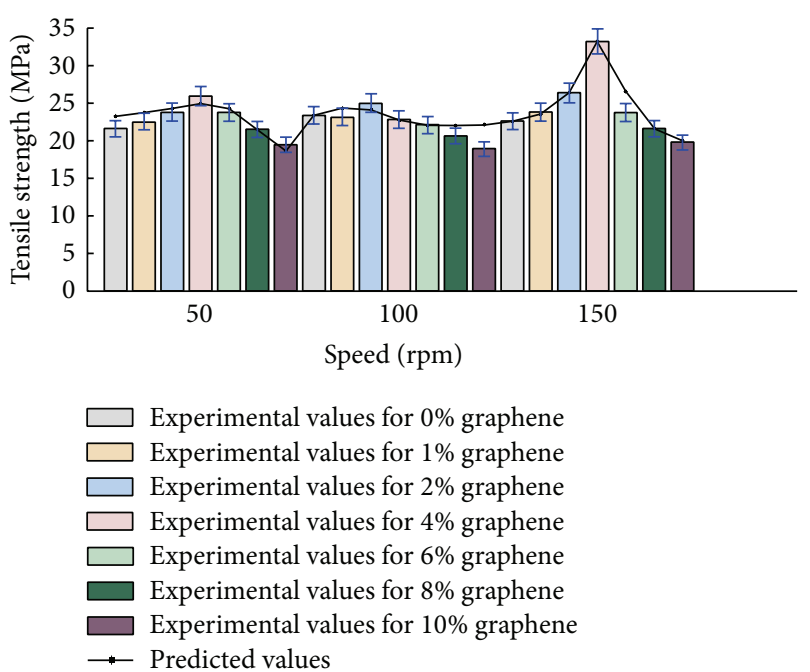

(b)

FIGURE 14: (a) Experimental versus predicted values of tensile strength of LLDPE/GNPs composites as a function of \% of graphene. (b) Experimental versus predicted values of tensile strength of LLDPE/GNPs composites as a function of speed.

TABLE 7: Prediction results of tensile strength for test samples.

\begin{tabular}{lccccc}
\hline Sample number & 4 & 5 & 6 & 17 & 21 \\
\hline $\begin{array}{l}\text { Measured value } \\
\text { (tensile strength } \\
(\mathrm{MPa}) \text { ) }\end{array}$ & 22.4 & 23.05 & 23.7 & 20.52 & 19.65 \\
$\begin{array}{l}\text { Predicted value } \\
\text { (tensile strength } \\
(\mathrm{MPa}) \text { ) }\end{array}$ & 23.66 & 24.21 & 23.39 & 21.88 & 19.88 \\
\hline
\end{tabular}

Moreover the good generalization capability of the network model is indicated by almost uniform values of correlation coefficient and mean square errors for training, validation, and testing data sets. The well-trained ANN method used in this study can be used to identify the relationships between the processing parameters and properties of the final products.

\section{Disclosure}

The statements made herein are solely the responsibility of the authors.

\section{Competing Interests}

The authors declare that they have no competing interests.

\section{Acknowledgments}

This work was made possible by NPRP Grant no. NPRP5039-2-014 from the Qatar National Research Fund (a member of Qatar Foundation).

\section{References}

[1] M. Karkri, M. Lachheb, D. Gossard, S. Ben Nasrallah, and M. A. AlMaadeed, "Improvement of thermal conductivity of paraffin by adding expanded graphite," Journal of Composite Materials, 2015.

[2] N. Shehata, N. Madi, M. Al-Maadeed, I. Hassounah, and A. Ashraf, "Improved electrical conductivity of carbon/polyvinyl alcohol electrospun nanofibers," Journal of Nanomaterials, vol. 2015, Article ID 812481, 5 pages, 2015.

[3] D. Ponnamma, K. K. Sadasivuni, C. Wan, S. Thomas, and M. AlAli AlMaadeed, Flexible and Stretchable Electronic Composites, Springer, New York, NY, USA, 2015.

[4] I. Krupa, M. Prostredny, Z. Špitalsky, J. Krajči, and M. A. S. Almaadeed, "Electrically conductive composites based on an elastomeric matrix filled with expanded graphite as a potential oil sensing material," Smart Materials and Structures, vol. 23, no. 12, Article ID 125020, 2014.

[5] J. Jose, M. A. Al-Harthi, M. A.-A. AlMa'adeed, J. B. Dakua, and S. K. De, "Effect of graphene loading on thermomechanical properties of poly(vinyl alcohol)/starch blend," Journal of Applied Polymer Science, vol. 132, no. 16, Article ID 41827, 2015.

[6] J. R. Potts, D. R. Dreyer, C. W. Bielawski, and R. S. Ruoff, "Graphene-based polymer nanocomposites," Polymer, vol. 52, no. 1, pp. 5-25, 2011.

[7] T. K. Das and S. Prusty, "Graphene-based polymer composites and their applications," Polymer-Plastics Technology and Engineering, vol. 52, no. 4, pp. 319-331, 2013.

[8] X. Huang, Z. Yin, S. Wu et al., "Graphene-based materials: synthesis, characterization, properties, and applications," Small, vol. 7, no. 14, pp. 1876-1902, 2011.

[9] M. A. Rafiee, J. Rafiee, Z. Wang, H. Song, Z.-Z. Yu, and N. Koratkar, "Enhanced mechanical properties of nanocomposites at low graphene content," ACS Nano, vol. 3, no. 12, pp. 38843890, 2009.

[10] J. Wang, H. Hu, X. Wang, C. Xu, M. Zhang, and X. Shang, "Preparation and mechanical and electrical properties of 
graphene nanosheets-poly(methyl methacrylate) nanocomposites via in situ suspension polymerization," Journal of Applied Polymer Science, vol. 122, no. 3, pp. 1866-1871, 2011.

[11] X. Zhao, Q. Zhang, D. Chen, and P. Lu, "Enhanced mechanical properties of graphene-based poly(vinyl alcohol) composites," Macromolecules, vol. 43, no. 5, pp. 2357-2363, 2010.

[12] X.-Y. Qi, D. Yan, Z. Jiang et al., "Enhanced electrical conductivity in polystyrene nanocomposites at ultra-low graphene content," ACS Applied Materials and Interfaces, vol. 3, no. 8, pp. 3130-3133, 2011.

[13] J.-E. An, G. W. Jeon, and Y. G. Jeong, "Preparation and properties of polypropylene nanocomposites reinforced with exfoliated graphene," Fibers and Polymers, vol. 13, no. 4, pp. 507-514, 2012.

[14] S. Kim and L. T. Drzal, "Comparison of exfoliated graphite nanoplatelets $(\mathrm{xGnP})$ and CNTs for reinforcement of EVA nanocomposites fabricated by solution compounding method and three screw rotating systems," Journal of Adhesion Science and Technology, vol. 23, no. 12, pp. 1623-1638, 2009.

[15] B. Mayoral, E. Harkin-Jones, P. N. Khanam et al., "Melt processing and characterisation of polyamide 6/graphene nanoplatelet composites," RSC Advances, vol. 5, no. 65, pp. 52395-52409, 2015.

[16] P. Noorunnisa Khanam and M. Al Ali AlMaadeed, "Processing and characterization of polyethylene-based composites," Advanced Manufacturing: Polymer \& Composites Science, vol. 1, no. 2, pp. 63-79, 2015.

[17] A. K. Jain, J. Mao, and K. M. Mohiuddin, "Artificial neural networks: a tutorial," Computer, vol. 29, no. 3, pp. 31-44, 1996.

[18] Z. Zhang and K. Friedrich, "Artificial neural networks applied to polymer composites: a review," Composites Science and Technology, vol. 63, no. 14, pp. 2029-2044, 2003.

[19] Matlab neural network toolbox, http://www.mathworks.com/ products/neural-network/.

[20] A. Abraham, "Artificial neural networks," in Handbook of Measuring System Design, P. Sydenham and R. Thorn, Eds., John Wiley \& Sons, London, UK, 2005.

[21] N. O. Attoh-Okine, "Analysis of learning rate and momentum term in backpropagation neural network algorithm trained to predict pavement performance," Advances in Engineering Software, vol. 30, no. 4, pp. 291-302, 1999.

[22] V. Cheung and K. Cannons, An Introduction to Neural Networks, Signal \& Data Compression Laboratory, Electrical \& Computer Engineering University of Manitoba, Winnipeg, Canada, 2002.

[23] B. L. Zhu, J. Wang, H. Zheng, J. Ma, J. Wu, and R. Wu, "Investigation of thermal conductivity and dielectric properties of LDPE-matrix composites filled with hybrid filler of hollow glass microspheres and nitride particles," Composites Part B: Engineering, vol. 69, pp. 496-506, 2015.

[24] W. Zhou, C. Wang, T. Ai, K. Wu, F. Zhao, and H. Gu, "A novel fiber-reinforced polyethylene composite with added silicon nitride particles for enhanced thermal conductivity," Composites Part A: Applied Science and Manufacturing, vol. 40, no. 6-7, pp. 830-836, 2009.

[25] J. Du and H.-M. Cheng, "The fabrication, properties, and uses of graphene/polymer composites," Macromolecular Chemistry and Physics, vol. 213, no. 10-11, pp. 1060-1077, 2012.

[26] X. Zhang, L. Shen, H. Wu, and S. Guo, "Enhanced thermally conductivity and mechanical properties of polyethylene $(\mathrm{PE}) /$ boron nitride $(\mathrm{BN})$ composites through multistage stretching extrusion," Composites Science and Technology, vol. 89, pp. 24-28, 2013.
[27] S. Mohamadi and N. Sharifi-Sanjani, "Investigation of the crystalline structure of PVDF in PVDF/PMMA/graphene polymer blend nanocomposites," Polymer Composites, vol. 32, no. 9, pp. 1451-1460, 2011.

[28] T. Kuila, S. Bose, A. K. Mishra, P. Khanra, N. H. Kim, and J. H. Lee, "Effect of functionalized graphene on the physical properties of linear low density polyethylene nanocomposites," Polymer Testing, vol. 31, no. 1, pp. 31-38, 2012.

[29] R. Koker, N. Altinkok, and A. Demir, "Neural network based prediction of mechanical properties of particulate reinforced metal matrix composites using various training algorithms," Materials \& Design, vol. 28, no. 2, pp. 616-627, 2007.

[30] V. Sridhar, I. Lee, H. H. Chun, and H. Park, "Graphene reinforced biodegradable poly(3-hydroxy-butyrate-co-4-hydroxybutyrate) nano composites," eXPRESS Polymer Letters, vol. 7, pp. 320-328, 2013.

[31] A. S. Patole, S. P. Patole, H. Kang et al., "A facile approach to the fabrication of graphene/polystyrene nanocomposite by in situ microemulsion polymerization," Journal of Colloid and Interface Science, vol. 350, no. 2, pp. 530-537, 2010.

[32] M. A. Milani, D. González, R. Quijada et al., "Polypropylene/graphene nanosheet nanocomposites by in situ polymerization: synthesis, characterization and fundamental properties," Composites Science and Technology, vol. 84, pp. 1-7, 2013.

[33] A. S. Patole, S. P. Patole, H. Kang, J. B. Yoo, T. H. Kim, and J. H. Ahn, "A facile approach to the fabrication of graphene/polystyrene nanocomposite by in situ microemulsion polymerization," Journal of Colloid and Interface Science, vol. 350, no. 2, pp. 530-537, 2010.

[34] Z.-X. Zhang, C. Gao, Z. X. Xin, and J. K. Kim, "Effects of extruder parameters and silica on physico-mechanical and foaming properties of PP/wood-fiber composites," Composites Part B: Engineering, vol. 43, no. 4, pp. 2047-2057, 2012. 

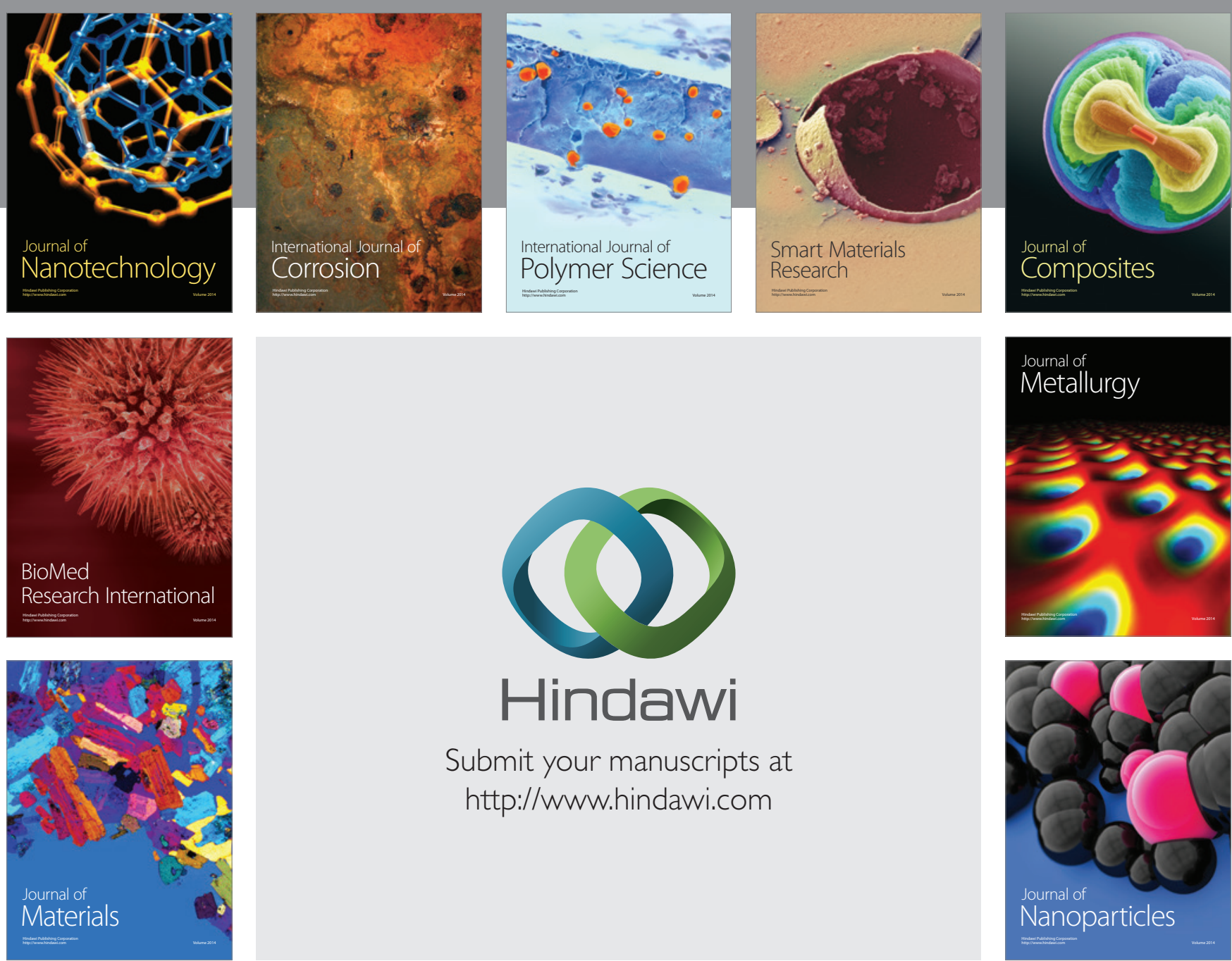

\section{Hindawi}

Submit your manuscripts at

http://www.hindawi.com

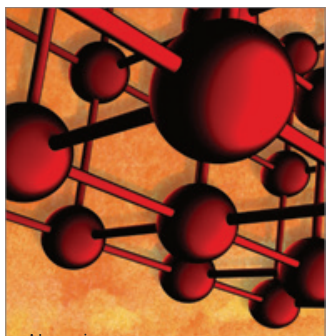

Materials Science and Engineering
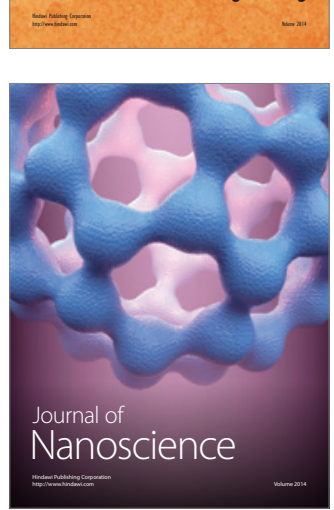
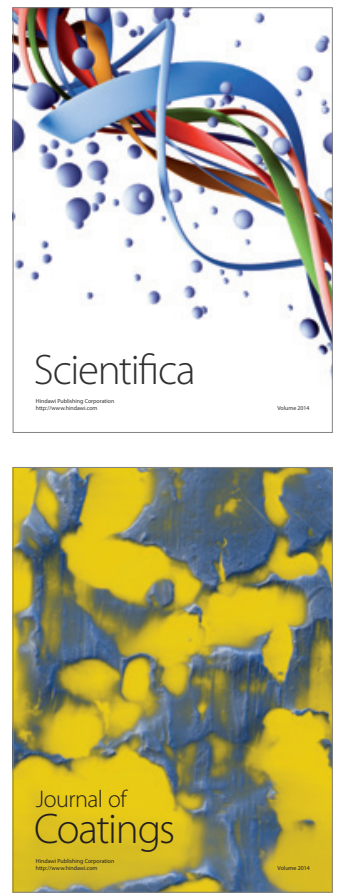
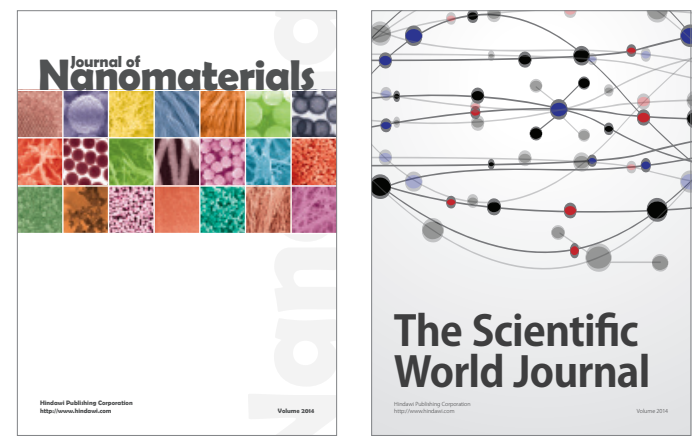

The Scientific World Journal
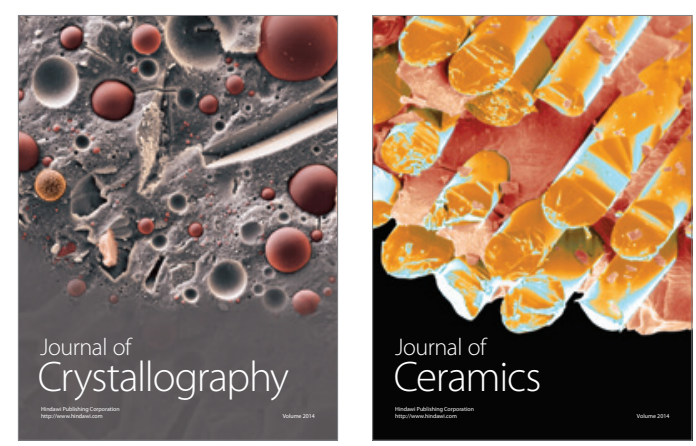
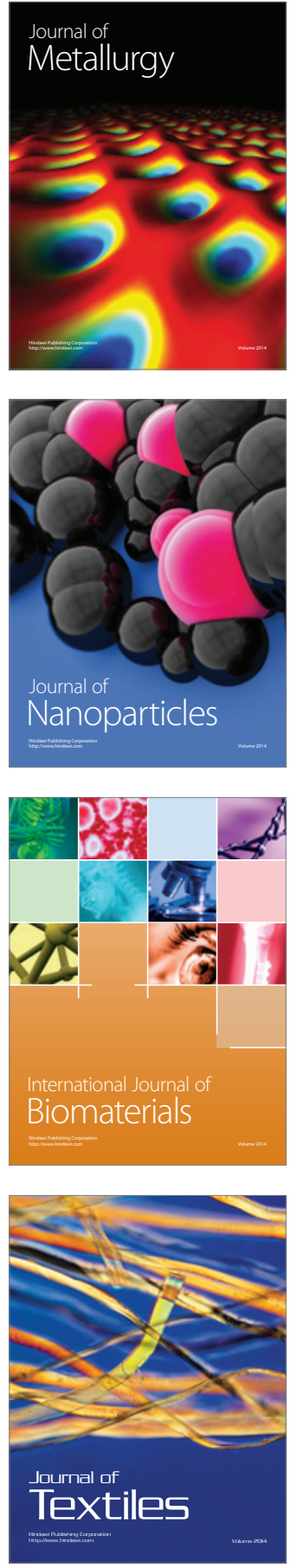